\title{
Atypical Hemolytic Uremic Syndrome: Update on the Complement System and What Is New
}

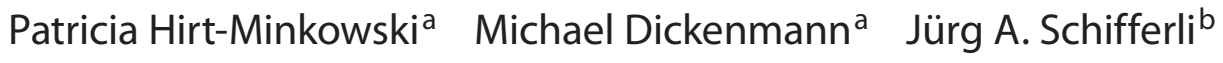 \\ Divisions of a Transplantation Immunology and Nephrology, and ${ }^{\mathrm{b}}$ Internal Medicine, University Hospital Basel, \\ Basel, Switzerland
}

\section{Key Words}

Hemolytic uremic syndrome - Complement system • Complement C3 $\cdot$ Complement factor $\mathrm{H} \cdot$ Factor I • Factor B • Membrane cofactor protein (CD46) • Plasma therapy • Transplantation

\begin{abstract}
Atypical hemolytic uremic syndrome (aHUS) is a rare disease of microangiopathic hemolytic anemia, thrombocytopenia, and predominant renal impairment. It is characterized by the absence of Shiga toxin-producing bacteria as a triggering factor. During the last decade, aHUS has been demonstrated to be a disorder of the complement alternative pathway dysregulation, as there is a growing list of mutations and polymorphisms in the genes encoding the complement regulatory proteins that alone or in combination may lead to aHUS. Approximately $60 \%$ of aHUS patients have so-called 'loss-of-function' mutations in the genes encoding the complement regulatory proteins, which normally protect host cells from complement activation: complement factor $\mathrm{H}$ (CFH), factor I (CFI) and membrane cofactor protein (MCP or CD46), or have 'gain-of-function' mutations in the genes encoding the complement factor B or C3. In addition, approximately $10 \%$ of aHUS patients have a functional CFH deficiency due to anti-CFH antibodies. Recent advances in under-
\end{abstract}

standing the pathogenesis of aHUS have led to a revised classification of the syndrome. Normal plasma levels of CFH and CFI do not preclude the presence of a mutation in these genes. Further, genotype-phenotype correlations of aHUS have clinical significance in predicting renal recovery and transplant outcome. Therefore, it is important to make a comprehensive analysis and perform genetic screening of the complement system in patients with aHUS to allow a more precise approach, especially before transplantation. This may also provide opportunities for more specific treatments in the near future, as complement inhibition could represent a therapeutic target in these patients who have a considerably poor prognosis in terms of both mortality and progression to end-stage renal disease and a great risk of disease recurrence after transplantation.

Copyright $\odot 2010$ S. Karger AG, Basel

\section{Introduction}

Thrombotic microangiopathy (TMA) was first described by Symmers [81] in 1952. It has been defined as a histopathological entity of several disorders including the 2 main syndromes, the hemolytic uremic syndrome (HUS) and thrombotic thrombocytopenic purpura (TTP), and a related syndrome that occurs during preg-

\section{KARGER}

Fax +4161306 1234 E-Mail karger@karger.ch www.karger.com (c) 2010 S. Karger AG, Basel

$1660-2110 / 10 / 1144-0219 \$ 26.00 / 0$

Accessible online at:

www.karger.com/nec
Patricia Hirt-Minkowski, MD

Division of Transplantation Immunology and Nephrology

University Hospital Basel

Petersgraben 4, CH-4031 Basel (Switzerland)

Tel. +41 61265 2525, Fax +41 61265 2410, E-Mail phirt@ uhbs.ch 


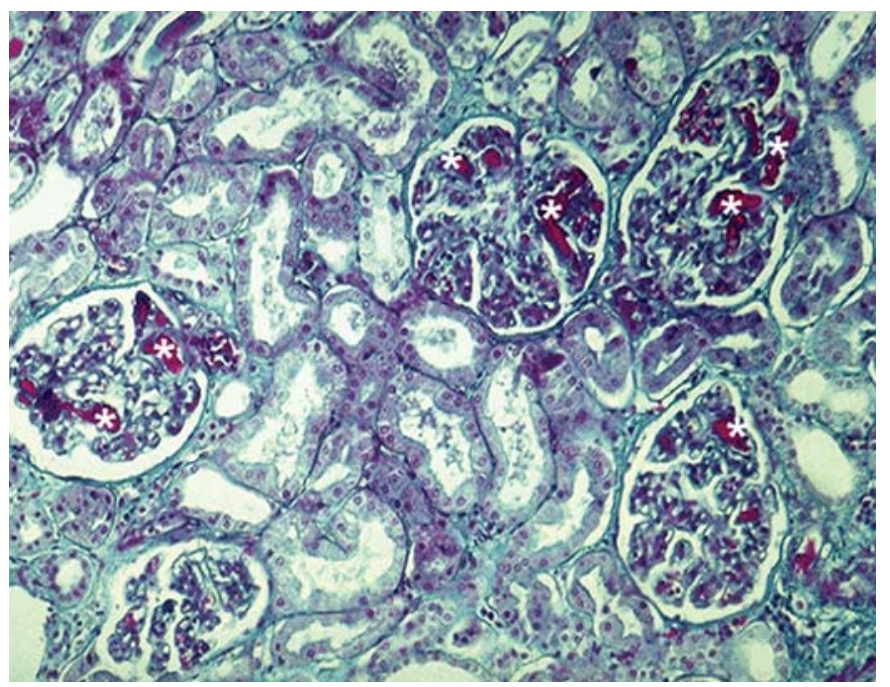

Fig. 1. Example of renal biopsy findings in TMA showing fibrin thrombi in the glomeruli (labeled with ${ }^{*}$ ).

nancy, i.e. the hemolysis, elevated liver enzyme, low platelet (HELLP) syndrome. TMA is characterized by the presence of fibrin and/or platelet thrombi in the microcirculation of various organs (fig. 1). The pathophysiology of TMA involves an initial endothelial cell injury induced by various factors and followed by occlusions of small arterioles and capillaries by platelet plugs and/or fibrin thrombi. The common clinical features are microangiopathic hemolytic anemia, thrombocytopenia and variable organ damage. Following the initial description of TTP by Moschcowitz [82]. in 1924 and HUS by Gasser and co-workers [83] in 1955, these 2 main syndromes of TMA had for a long time been distinguished considering only clinical aspects: HUS characterized by predominant renal involvement, i.e. acute renal failure, and TTP, of which predominant neurological involvement is a feature. However, the clinical presentation of these disorders can overlap and many factors can trigger HUS such as Shiga toxin (Stx)-producing enterobacteria, especially enterohemorrhagic Escherichia coli serotype 0157:H7 (VTEC/STEC), or in some tropical regions Shigella dysenteriae type 1, which is the most frequent form of HUS, with predominant occurrence in children called typical or postdiarrheal (D+) HUS [1], but also by pneumococcal (via neuraminidase of Streptococcus pneumoniae and T antigen exposure) and human immunodeficiency virus infections, metastatic cancers, organ and stem cell transplantation, autoimmune diseases or drugs and it even occurs without any identifiable trigger [2].
Table 1. Classification [modified from 11]
Etiology advanced

1 Infection induced

a Stx-producing bacteria; enterohemorrhagic

E. coli, S. dysenteriae type 1, Citrobacter

b S. pneumoniae, neuraminidase, and $\mathrm{T}$ antigen exposure

c Other infectious agents

2 Disorders of complement regulation

a Genetic disorders of complement regulation

b Acquired disorders of complement regulation, for example anti-CFH antibodies

3 Von Willebrand proteinase, ADAMTS13 deficiency

a Genetic disorders of ADAMTS13

b Acquired von Willebrand proteinase deficiency: autoimmune, drug induced

4 Defective cobalamine metabolism

5 Drug induced (quinine)

Clinical associations: etiology unknown

1 Human immunodeficiency virus

2 Malignancy, cancer chemotherapy and ionizing radiation

3 Calcineurin inhibitors and transplantation

4 Pregnancy, HELLP syndrome and oral contraceptive pill

5 SLE and antiphospholipid antibody syndrome

6 Glomerulopathy

7 Familial, not included in part 1

8 Unclassified

SLE $=$ Systemic lupus erythematosus.

Over the past decade, clinical and basic research has improved our understanding of the pathogenesis of TMA and helped to distinguish HUS from TTP. There have been 2 major breakthroughs. The first was the identification that ADAMTS13 (a disintegrin-like and metalloprotease with thrombospondin type 1 repeats) deficiency is more likely to present with the insidious or fluctuating neurological signs of adult idiopathic TTP [3-6]. But even severe ADAMTS13 deficiency does not account for all cases of idiopathic TTP [7]. The second was the finding that abnormal control of the alternative complement pathway is a risk factor for atypical HUS (aHUS) [8, 9]. These results led to the recent proposal to use the terms of 'ADAMTS13deficiency-related TMA' and 'complement-dysregulationrelated TMA' rather than the terms TTP and HUS [10].

In 2006, the European Paediatric Research Study group for HUS [11] published a revised classification of HUS, TTP and related disorders, based on the contemporary understanding of causation which can also be adopted for adult patients and is still accurate (summarized in table 1). In brief, patients can be classified as follows: 


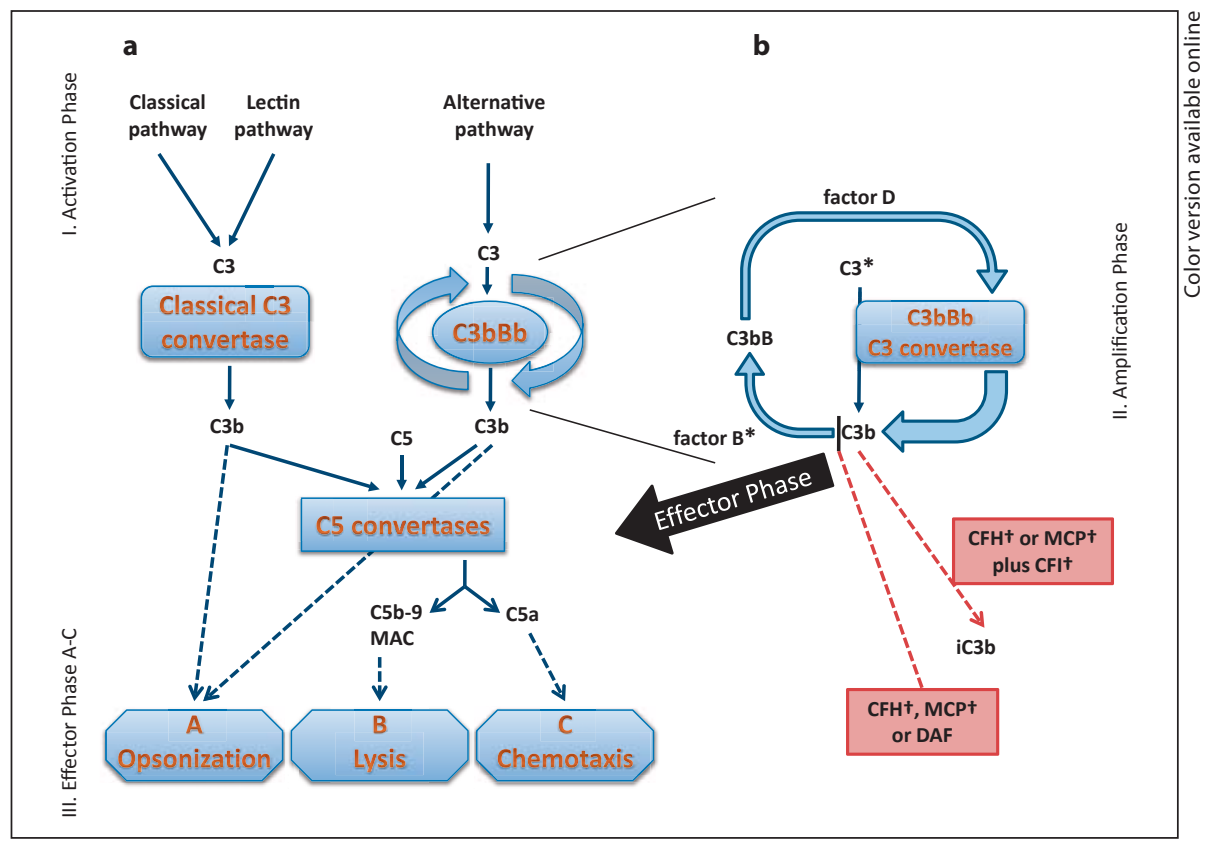

Fig. 2. Complement activation and control. a Activation of the complement system proceeds by 3 pathways: the classical, the lectin and the alternative pathway. Activation sets in motion a cascade by which inactive zymogens convert to active proteins and the generation of the $\mathrm{C} 3$ convertase of the classical/lectin and the alternative pathway $(\mathrm{C} 3 \mathrm{bBb})$ as the critical step in complement activation. All 3 pathways converge at the point of cleavage of C3 and have a common effector phase, initiating inflammation and microbial defense: (A) deposition of C3b molecules on the surface of microbes (opsonization), (B) formation of the terminal complex C5b-9 (MAC), which results in lysis of microbes or (C) releasing of anaphylactic products such as $\mathrm{C} 5 \mathrm{a}$ (chemotaxis). b Covalent binding of $\mathrm{C} 3 \mathrm{~b}$ on foreign surfaces such as microbes leads to binding of $\mathrm{CFB}$, which is then cleaved by factor $\mathrm{D}$ to form the $\mathrm{C} 3$ convertase of the alternative pathway $\mathrm{C} 3 \mathrm{bBb}$, providing exponential cleavage of $\mathrm{C} 3 \mathrm{~b}$ (the amplification phase of alternative complement pathway), and formation of the C5 convertase and of the MAC (the effector phase). Protection of host cells from formation of $\mathrm{C} 3 \mathrm{bBb}$ on their surface is provided by soluble and membrane-associated complement regulatory proteins such as $\mathrm{CFH}$, CFI and MCP, respectively. Dysfunction of regulatory proteins by so-called 'loss-of-function' gene mutations (labeled with ${ }^{\dagger}$ ) or antibodies against $\mathrm{CFH}$ and gain-of-function mutations in the genes encoding CFB and C3 (labeled with *) lead to uncontrolled activation of the alternative complement pathway (described in detail in the text). in the upper part, the cause is well established and in the lower part, disease or drug associations may be described but causation is not proven. The revised classification is in line with the idea that HUS can be caused by either, or both, an external environmental trigger and/or an intrinsic inherited risk factor and that in an individual patient the disease may have several etiologies. For example, a patient with complement factor $\mathrm{H}(\mathrm{CFH})$ gene mutation might present with an episode of HUS precipitated by infection, perhaps even classical enterohemorrhagic E. coli infection.

The aim of this review is to summarize the evident understanding of the pathophysiology of aHUS, the association with complement dysregulation, to discuss treatment guidelines and, last but not least, to work out the future treatment options.

Update on the Complement System

\section{The Complement System and Its Regulation}

The complement system is an essential component of innate immunity with crucial roles in killing microorganisms, apoptotic cell clearance, bridging of innate and adaptive immunity and production of anaphylatoxins. Complement is activated by 3 pathways: the classical pathway, the lectin pathway and the alternative pathway [12]. These 3 pathways converge at the point of cleavage of $\mathrm{C} 3$ and have a common effector phase, initiating inflammation and microbial defense: (A) deposition of $\mathrm{C} 3 \mathrm{~b}$ molecules on the surface of microbes (opsonization), (B) formation of the terminal complex C5b-9 (the membrane attack complex, MAC), which results in lysis of microbes and $(\mathrm{C})$ release of anaphylactic products such as C3a and C5a (fig. 2a). The alternative complement pathway is ini-

Nephron Clin Pract 2010;114:c219-c235 
tiated by the autoactivation of $\mathrm{C} 3$, the formation of a $\mathrm{C} 3$ convertase, followed by the generation of $\mathrm{C} 3 \mathrm{~b}$. The $\mathrm{C} 3 \mathrm{~b}$ formed binds indiscriminately to surfaces as microbes and host cells. Covalent binding of $\mathrm{C} 3 \mathrm{~b}$ to pathogens leads to formation of further $\mathrm{C} 3$ convertases, providing the exponential cleavage of $\mathrm{C} 3 \mathrm{~b}$ (the amplification phase of complement activation) leading to MAC formation.

The uncontrolled activated complement system has devastating effects; therefore, host cells are protected from damage 'to self' and consumption of components of the complement system by soluble and membrane-associated regulatory proteins, which keep the system in track and provide local protection of host cells. This local control system ensures that activation is mainly targeted to quickly remove invading pathogens. The importance of these regulators is demonstrated by the fact that there are almost as many regulatory proteins as there are proteins in the complement activation cascade [12]. The complement regulators have 2 main mechanism of action: decay acceleration activity (i.e. decay of the $\mathrm{C} 3$ convertase) and cofactor activity. CFH is a fluid-phase regulator that has cofactor activity for the cleavage of $\mathrm{C} 3 \mathrm{~b}$ by complement factor I (CFI), and, in addition, has decay acceleration activity. $\mathrm{CFH}$ is a most important complement regulator. For its cleaving function, the fluid-phase serine protease $\mathrm{CFI}$ is dependent on cofactor activity. The membrane cofactor protein (MCP or CD46) is a resident transmembrane protein expressed on almost every human cell except erythrocytes. It is the second important cofactor for CFI for the cleavage of $\mathrm{C} 3 \mathrm{~b}$ and further promotes the decay of the $\mathrm{C} 3$ convertase. The activation and regulation of the alternative pathway is shown in figure $2 \mathrm{~b}$.

The impairment of the alternative pathway regulation leads to excessive liberation of different cleavage fragments such as the anaphylatoxins C3a and C5a and the unrestricted formation of the MAC. All components mediate different signaling pathways [13-16], leading to inflammation and platelet activation, and especially the MAC is capable of participating in the microangiopathic lesions of the kidney as shown in animal models [1719].

\section{aHUS Associated with Gene Mutations in Complement Regulatory Proteins}

Nondiarrheal HUS or aHUS is a clinically defined form of TMA characterized by predominantly renal involvement, absence of Stx-producing bacteria as a triggering factor and is associated with relapses and a poor outcome. Overall, aHUS is less common than Stx-associated HUS and accounts for only $5-10 \%$ of all cases of HUS [9].

In 1981, Thompson and Winterborn [20] described the correlation of hypocomplementemia (i.e. reduced C3 level) and the involvement of the alternative complement pathway in the pathogenesis of aHUS. In 1998, Warwicker et al. [21] reported a link between aHUS and a region of chromosome 1q32 by genetic studies of 3 large families. This region contains a group of genes that have a central role in the regulation of complement activation: the regulators of complement activation (RCA) gene cluster. The innovative report of Warwicker et al. [21] and the subsequent descriptions of different mutations, all within genes encoding regulatory proteins of the alternative pathway, provided substantial evidence that uncontrolled activation of complement plays a central role in the pathogenesis of aHUS [8, 22-25].

Nowadays, aHUS can be described as a disease of alternative pathway dysregulation. There is a growing list of mutations and polymorphisms in genes encoding complement regulatory proteins that alone or in combination may lead to aHUS. The most frequently reported mutations are in the gene encoding $\mathrm{CFH}$ and account for $50-60 \%$ of cases associated with documented genetic abnormalities. Mutations in the genes encoding MCP and CFI are observed in approximately 20 and $10-15 \%$ of the overall disease-associated mutations, respectively (data from registries $[22,24,26]$ and individual centers). Importantly, mutations in the genes encoding regulatory proteins are so called 'loss-of-function' mutations. There are now reports emerging that 'gain-of-function' mutations in the genes encoding factor $\mathrm{B}$ (CFB) or $\mathrm{C} 3$ have also been detected in a few patients with aHUS $[27,28]$. These data expand our understanding of the critical role of the alternative pathway in the pathogenesis of aHUS. The incidence of mutations in proteins of the alternative pathway in patients with aHUS is illustrated in table 2.

\section{Complement Factor $H$}

Mainly synthesized by the liver, $\mathrm{CFH}$ is a single polypeptide chain glycoprotein of $150 \mathrm{kDa}$ composed of 20 repetitive units of 60 amino acids, named short consensus repeats (SCR), arranged in a continuous fashion [29]. The CFH molecule includes different interaction sites for $\mathrm{C} 3 \mathrm{~b}$ and polyanions (fig. 3). The C3b binding site in SCR1-4 is the only site essential for the CFI cofactor activity of CFH. Similarly, the C3b/polyanions-binding site located within SCR19-20 is the most important site for preventing alternative complement pathway activation 
Fig. 3. Structure of CFH with the 20 SCR arranged in continuous fashion and its functional domains. $\mathrm{CFH}$ has $3 \mathrm{C} 3 \mathrm{~b}$-binding sites: SCR1-4, SCR12-14 and SCR1920 , respectively. Similarly, a total of 3 separate binding sites for heparin and sialic acid have been identified in SCR7, SCR13 and SCR19-20, respectively. The critical sites for cofactor activity/decay accelerating activity and cell surface regulation at the $\mathrm{N}$ - and C-terminal sites, respectively, are indicated.

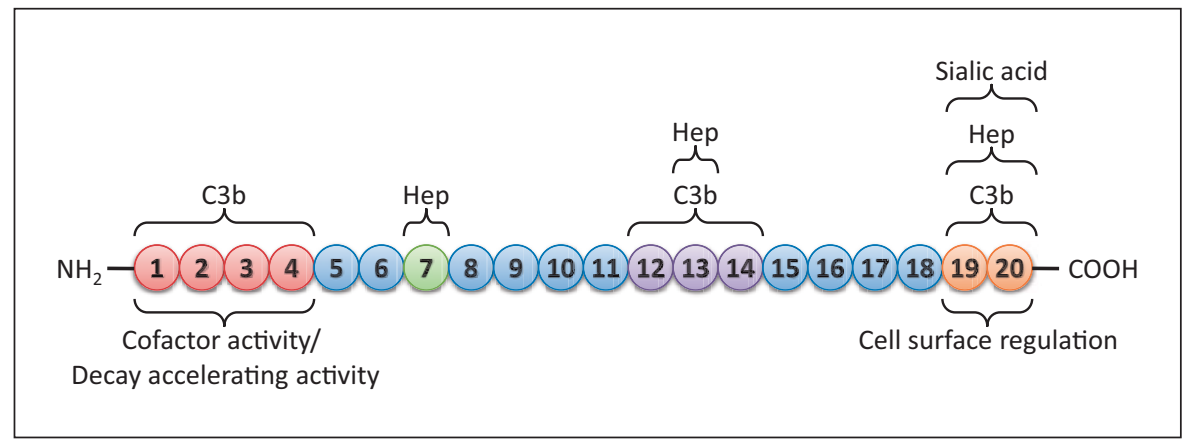

Table 2. Incidence of mutations in proteins of alternative complement pathway in patients with aHUS

\begin{tabular}{llll}
\hline Gene & Location & $\begin{array}{l}\text { Frequency } \\
\text { in aHUS, } \%\end{array}$ & Ref. No. \\
\hline CFH & RCA gene Chr 1 & $10-30$ & $8,22-24,26,34$ \\
MCP & RCA gene Chr 1 & $10-15$ & $8,22-24,34,41$ \\
CFI & Chr 4 & $5-10$ & $8,22,34,42,43$ \\
CFB & Chr 6 & $0-3$ & 27 \\
C3 & Chr 19 & N/A & 28 \\
\hline
\end{tabular}

Chr $=$ Chromosome; N/A = not available.

on host cells, showing distinct functional domains at the $\mathrm{N}$ - and C-terminal site of the $\mathrm{CFH}$ molecule, respectively [30]. Extrahepatic synthesis of CFH also occurs in a wide variety of cell types, such as glomerular mesangial cells, retinal pigment epithelial cells, peripheral blood lymphocytes, myoblasts, fibroblasts, umbilical vein endothelial cells, or neurons. The extrahepatic synthesis of CFH is interpreted as a mechanism to increase the local concentration of CFH for the protection of host cells from complement activation in sites of infection or inflammation.

In the human plasma, there are 6 proteins that are structurally related and cross-react immunochemically with CFH. Factor H-like protein FHL-1 is the product of alternative splicing of the gene-encoding $\mathrm{CFH}$ [31] and in addition there are 5 related proteins (CFHR1, CFHR2, CFHR3, CFHR4, CFHR5), that are encoded by 5 different genes [32]. These proteins are probably synthesized by the liver, but their concentrations in the plasma are much lower than that of $\mathrm{CFH}$ and their functional properties are not defined completely. The $\mathrm{CFH}$ gene is a member of the RCA gene cluster on chromosome 1q32 [33]. At present, 100 distinct $\mathrm{CFH}$ gene mutations or polymorphisms have been reported in aHUS patients [34]. All reported mutations were heterozygous, except in 15 patients (mostly from consanguineous families) with homozygous $\mathrm{CFH}$ deficiency [35] and a few cases of compound heterozygous mutations. The majority of mutations published up to now have been located within the C-terminal domain of the protein, particularly in SCR20 revealing a hot spot for mutations as shown in figure 4 . Carriers of mutations in SCR19-20 express CFH molecules with a reduced ability to bind to surfaces, including polyanions of the endothelial cell and, thus, have limited capacity to protect host surfaces from alternative pathway activation but present normal regulatory (cofactor) activity in the fluid phase, i.e. in the plasma [36]. This limited complement regulatory capacity could lead to specific susceptibility to the development of aHUS as a situation of 'autolesion' caused by uncontrolled activation of complement in the kidneys.

It is interesting to note that only a few reported CFH gene mutations have been associated with quantitative $\mathrm{CFH}$ deficiency as defined by an antigenic plasma level below half normal; however, the antigenic level was not determined in every case [8].

In recent years, considerable evidence has been generated to support the hypothesis that both the membranoproliferative glomerulonephritis type II (MPGN2) and age-related macular degeneration (AMD) are further diseases caused by dysregulation of the alternative complement pathway. Several reports illustrate a remarkable genotype-phenotype correlation in which distinct genetic variations and mutations of $\mathrm{CFH}$ and related proteins predispose specifically to MPGN2, AMD or aHUS. In particular, the CFH His402 variant in SCR7 of CFH has consistently been shown to be associated with increased risk to develop AMD in numerous studies [37]. MPGN2 is associated with $\mathrm{CFH}$ gene mutations or autoantibodies directed against CFH but is also associated with autoan- 
Fig. 4. The majority of the gene mutations associated with aHUS cluster in the C-terminal region of $\mathrm{CFH}$. The structure of CFH is shown with the 20 SCR and the most representative mutations reported in the literature are indicated. The majority of mutations in the CFH gene are missense mutations, resulting in a single amino acid exchange.

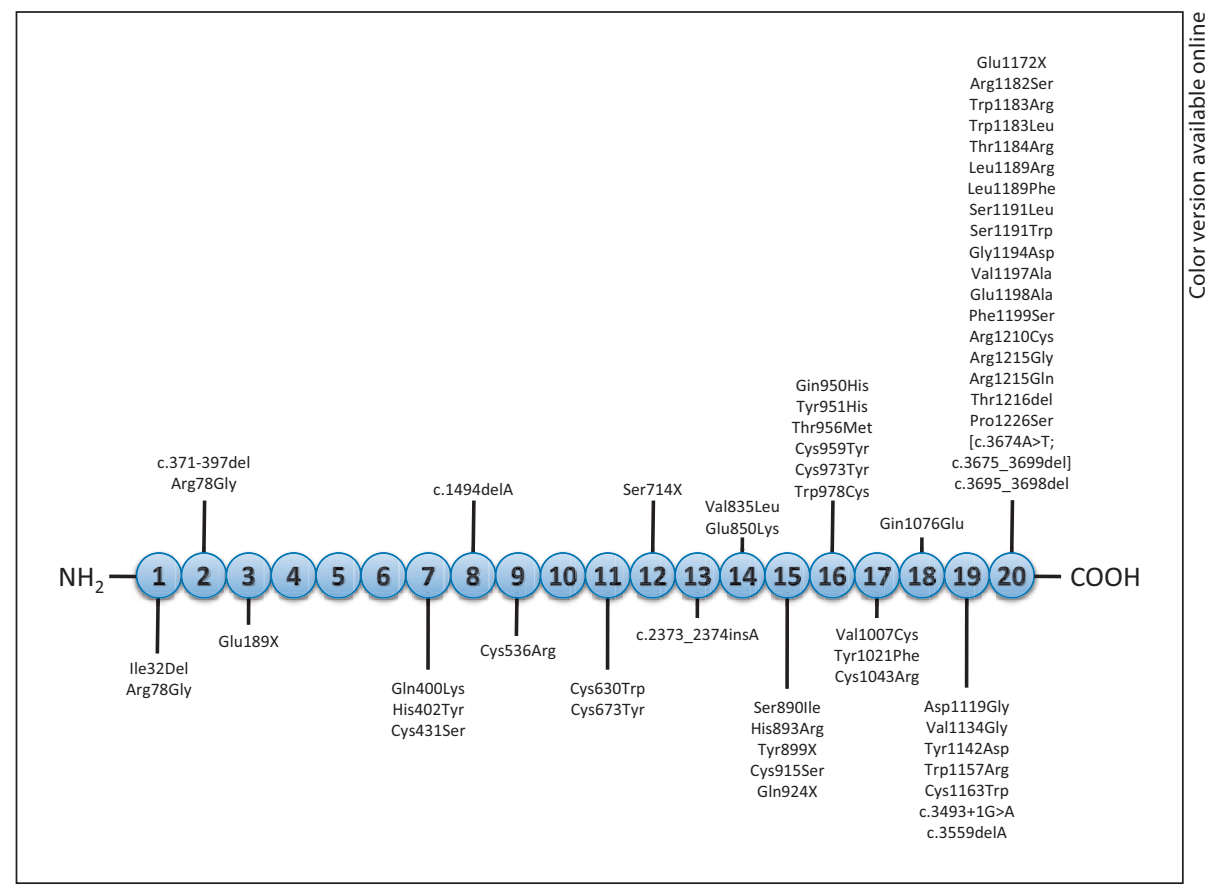

tibodies directed against the $\mathrm{C} 3$ convertase of the alternative pathway called $\mathrm{C} 3 \mathrm{NeF}$. The coincidence of $\mathrm{CFH}$ deficiencies with strong complement activators such as $\mathrm{C} 3 \mathrm{NeF}$ may be critical in the development of MPGN2 instead of aHUS. Interestingly, MPGN2 also associates with alleles of CFH and CFHR5 genes. A more extensive description of MPGN2 or AMD and the association with defective alternative pathway control have been given previously [38].

\section{$M C P(C D 46)$}

$\mathrm{MCP}$ is a widely expressed transmembrane glycoprotein that inhibits complement activation on host cells by serving as a membrane-bound cofactor for the plasma serine protease $\mathrm{CFI}$ to cleave $\mathrm{C} 3 \mathrm{~b}$ and $\mathrm{C} 4 \mathrm{~b}$. The $\mathrm{N}$-terminal site of MCP consists of 4 SCR. This extracellular portion of MCP is followed by a hydrophobic transmembrane domain and a cytoplasmatic anchor. Sites for $\mathrm{C} 3 \mathrm{~b}$ and $\mathrm{C} 4 \mathrm{~b}$ interactions have been mapped to SCR2, SCR3 and SCR4 [39]. The MCP gene is located within the RCA gene cluster on chromosome 1q32 and therefore was considered to be a candidate gene for mutations in patients with aHUS [40]. Richards et al. [41] identified for the first time functionally significant MCP gene mutations in 7 patients ( 3 pedigrees) presenting a family history of aHUS with a recessive form of inheritance. Since then, 25 disease-associated mutations due to homozygous, heterozy- gous or compound heterozygous forms of inheritance and 5 disease-associated polymorphisms have been identified [34]. Most of the mutations were found in the $4 \mathrm{~N}$ terminal SCR domains with the exception of 1 mutation found in the transmembrane domain. To illustrate this, figure 5 shows the location of the MCP gene mutations which have been identified in Italian and French cohorts of aHUS patients $[22,24]$. Over $80 \%$ of all reported mutations caused a reduction in MCP surface expression, whereas as small proportion resulted in only a functional defect. Further, in the French cohort, 2 individuals were described for the first time without any surface expression of MCP. Serum C3 levels in patients with MCP gene mutations were normal or slightly lower than normal, leading to the hypothesis that local dysregulation of the complement system in the kidney by reduced cofactor activity of mutant MCP predisposes to severe TMA in the renal vasculature.

\section{Complement Factor I}

CFI is a 2-chain serine protease in which the light chain carries the catalytic domain, while the function of the heavy chain, containing 2 low-density lipoprotein receptor domains and a CD5 domain (also called FIMAC), is unclear. CFI is predominantly synthesized by the liver and downregulates the alternative pathway by cleaving $\mathrm{C} 3 \mathrm{~b}$, but is efficient only in the presence of cofactor pro- 
teins (i.e. CFH and MCP). The CFI gene is located outside the RCA gene cluster on chromosome 4q25 [8].

In 2004, Frémeaux-Bacchi et al. [42] reported for the first time the clinical courses of 3 aHUS patients presenting with mutations in the CFI gene. Today, the database contains a total of 16 disease-associated mutations in the CFI gene and the majority of these mutations are within the catalytic domain of the light chain [34]. Further, most CFI gene mutations induce a lack of protein synthesis, and only few mutations have been associated with a functional deficiency. CFI gene mutations appear to be a less common cause of aHUS (between 5 and $10 \%$ of all aHUS patients) than are CFH and MCP gene mutations $[22,24$, $42,43]$.

\section{Recent Identification of Gain-of-Function Mutations}

Goicoechea de Jorge et al. [27] identified a subgroup of aHUS patients without mutations in the genes encoding complement regulatory proteins, showing persistent activation of the alternative pathway with very low serum levels of C3 and normal or elevated serum levels of C4. They found within that subgroup 2 families with heterozygous mutations in the gene encoding CFB. CFB is a zymogen that carries the catalytic site of the alternative pathway convertase $\mathrm{C} 3 \mathrm{bBb}$. Upon interaction with $\mathrm{C} 3 \mathrm{~b}$, $\mathrm{CFB}$ is cleaved by complement factor $\mathrm{D}$ into 2 fragments, $\mathrm{Ba}$ and $\mathrm{Bb}$. $\mathrm{Ba}$ is released and $\mathrm{Bb}$ remains bound to $\mathrm{C} 3 \mathrm{~b}$, forming the convertase $\mathrm{C} 3 \mathrm{bBb}$, an active serine protease that cleaves additional $\mathrm{C} 3$ into $\mathrm{C} 3 \mathrm{~b}$ as shown in figure $2 \mathrm{~b}$. Functional analysis demonstrated that aHUS-associated CFB gene mutations are gain-of-function mutations that result in enhanced formation of $\mathrm{C} 3 \mathrm{bBb}$ convertase or increased resistance to inactivation by complement regulatory proteins. Taken together, these data highlight that alternative pathway overactivation by gain-of-function mutations may lead to the pathogenesis of aHUS, although mutations in the CFB gene are rare, accounting for $0-3 \%$ of disease-associated mutations [34].

Further, the group of Frémeaux-Bacchi et al. [28] described in 2 independent cohorts (Newcastle and Paris) 9 novel distinct mutations of complement $\mathrm{C} 3$ in 14 patients with aHUS with persistently low serum C3 levels. Functional assays were performed with 7 expressed C3 mutants to assess the interaction of the secreted C3 mutants with MCP and demonstrated that 5 of these $\mathrm{C} 3$ mutants had decreased MCP binding and cofactor activity. Thus, the reduced interaction of these 5 of the 7 secreted C3 mutants with MPC is likely to induce gain of function relative to alternative pathway activation [28].

Update on the Complement System

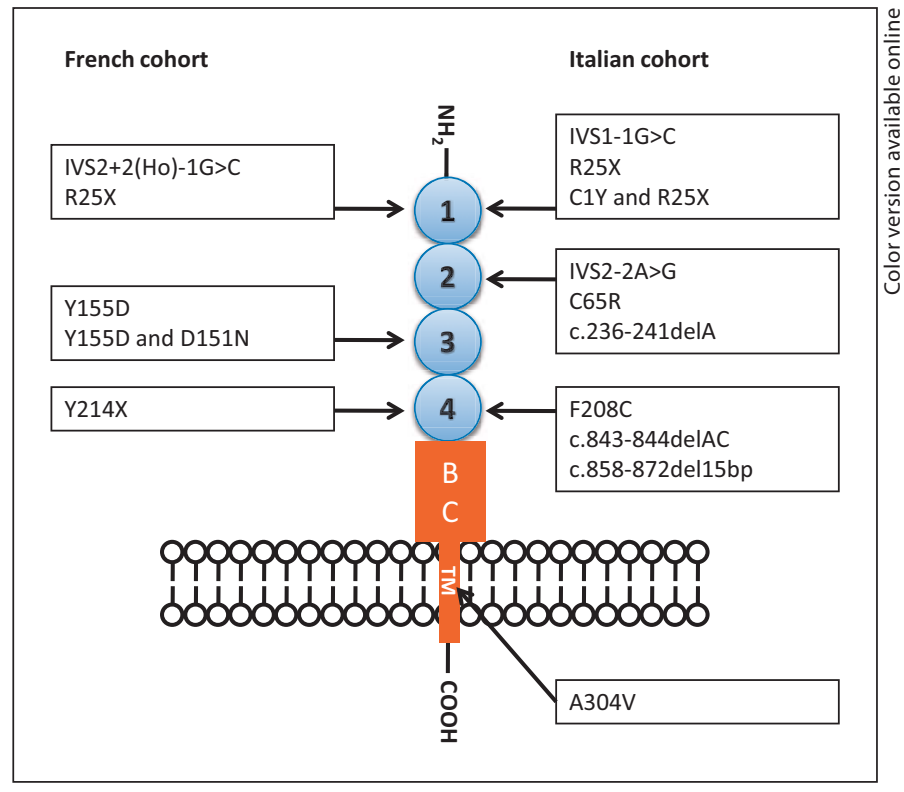

Fig. 5. Summary of the MCP gene mutations located within the SCR1-4 domains and 1 mutation within the transmembrane domain form the Italian (right) and the French (left) cohort. TM = Transmembrane domain.

\section{Combined Mutations in aHUS, Other Susceptibility Factors and Genetic Variability}

Mutations in genes encoding complement proteins are identified in at least $50 \%$ of cases with familial or sporadic aHUS reported in the literature. It is important to note that about $10 \%$ of patients have combined mutations, especially of CFI gene mutations with either $\mathrm{CFH}$ or MCP gene mutations [22]. Penetrance of aHUS associated with mutations in genes encoding regulatory proteins or complement activators has been reported to be approximately $50 \%$ in all series, suggesting that the inheritance of a single mutation may be insufficient to cause aHUS by itself.

To identify additional aHUS susceptibility factors, the regulator genes have been analyzed further in genetic association studies $[44,45]$. These and subsequent replication studies [27, 46-48] demonstrated 2 relatively frequent $\mathrm{CFH}$ and $\mathrm{MCP}$ gene alleles $(\mathrm{CFH}-\mathrm{H} 3$ and $M C P g g a a c$ haplotypes) that were significantly more frequent in aHUS patients (either with or without $\mathrm{CFH}, \mathrm{MCP}$, CFI, or CFB gene mutations) than in controls. Moreover, it could be shown that family members with complement regulatory or CFB gene mutations developing aHUS had inherited the allele carrying the genetic mutation from one parent and the allele carrying the disease-associated $\mathrm{CFH}$ and/or MCP gene haplotype from the other parent. Most 
interestingly, the healthy $\mathrm{CFH}, \mathrm{MCP}, \mathrm{CFI}$ or $\mathrm{CFB}$ gene mutation carriers in these families did not inherit the aHUSassociated $\mathrm{CFH}$ and/or MCP gene polymorphism. Although additional studies are needed to fully characterize the role of these $\mathrm{CFH}$ and MCP gene haplotypes, the association of $\mathrm{CFH}-\mathrm{H} 3$ and MCPggaac haplotypes with aHUS is important because it indicates that polymorphism of the genes encoding $\mathrm{CFH}$ and MCP may predispose to aHUS in the absence of other mutations and that even in carriers of mutations, additional regulator gene variants may be needed for the development of the disease ('multiple-hit hypothesis') [38]. In practice, the implication of incomplete penetrance of the disease within families is that it is not possible for an individual family member presenting with a mutation and/or risk polymorphism to forecast the risk of the occurrence of aHUS. Even so, environmental triggers or precipitating events also appear to be a prerequisite for the development of the disease. In summary, mutations in genes encoding complement regulatory proteins or complement activators predispose to aHUS rather than they are causative per se.

\section{Acquired Dysregulation of the Alternative Complement Pathway}

In addition to gene mutations encoding complement regulatory proteins, $\mathrm{CFH}$ autoantibodies leading to an acquired functional $\mathrm{CFH}$ deficiency have been reported in aHUS patients, mostly in children [49-51]. The binding epitopes of the autoantibodies were localized to the $\mathrm{C}$-terminal recognition region of $\mathrm{CFH}$. This overlap with the majority of mutations within the C-terminal domain of the protein, particularly in SCR20, suggests similar functional consequences for the $\mathrm{CFH}$ autoantibodies and for the genetic mutations. Interestingly, individuals presenting with $\mathrm{CFH}$ autoantibodies are, with very few exceptions, homozygous for the deletion of the CFHR1 and CFHR3 genes. Whether the deletion of these genes and the presence of $\mathrm{CFH}$ autoantibodies are independent risk factors for aHUS remains unclear.

\section{Clinical Characteristics of aHUS Associated with Alternative Complement Dysregulation}

In the last decade, data from registries $[22,24,26]$ and individual centers have made it possisble to study the clinical characteristics of aHUS in accordance with the identified risk factors.

\section{Triggering Events}

It is worth noting that there is a high frequency of infectious triggering events in patients with aHUS, especially upper respiratory tract infections, fever and diarrhea $[22,24]$. Diarrhea preceded aHUS in nearly $30 \%$ of patients from all subgroups, including Stx-associated bloody diarrhea in one child with an MCP gene mutation [24]. Harboring a MCP gene mutation could probably be a risk factor for a severe outcome of Stx-associated HUS, as a 4-year-old patient with an MCP gene mutation died from multivisceral involvement after Stx-associated HUS [52]. Another observation of an adult patient with a CFH gene mutation and severe diarrhea-positive HUS has also been reported [53].

\section{Age at Onset of the Disease}

Stx-associated HUS is the most common cause of acute renal failure in childhood [1]; on the other hand, aHUS may manifest at all ages but is more frequent in adolescent and adult patients [54]. Early age at onset in children appears to be characteristic of aHUS associated with $\mathrm{CFH}$ and CFI gene defects, while aHUS associated with MCP gene mutations is not seen before the age of 1 year [22, 24].

\section{Familial aHUS}

The incidence of familial aHUS ranged from less than $10 \%$ in the aHUS registry of the German-speaking countries [26] to $25 \%$ in the French [24] and 37\% in the Italian aHUS registry [22], respectively, and the gender ratio was equilibrated. The frequency of familial aHUS is similar in the groups with CFH, MCP and CFI gene mutations and in the group with no mutation. Most frequently in familial aHUS, the disease occurs in siblings but may also be present in different generations. The absence of a family history of aHUS does not exclude the possibility of a genetic transmission of the disease.

\section{Clinical Course and Outcome}

Extrarenal involvement during HUS flares in aHUS patients with alternative complement dysregulation is very rare. Involvement of the central nervous system is found in around $30 \%$ of children with typical HUS and in these patients, it is the most common cause of mortality [55]. Concerning data from registries of aHUS patients $[22,24,26]$ the clinical characteristics are best described in the French pediatric cohort (46 children). Fewer than $10 \%$ of these patients had extrarenal involvement (4 patients, including 1 with CFH mutation, and 3 with unexplained HUS had cerebrovascular events, 1 of these 
patients had pulmonary involvement, too) [24]. Moreover, information obtained from literature research is poor. We found a single case report of a male child with congenital homozygote CFH deficiency who had an ocular hemorrhagic and ischemic involvement in one eye after 3 years of uneventful hemodialysis [56]. Ocular TMA has never been reported in patients with $\mathrm{CFH}$ mutations before but has recently been reported in a few pediatric patients with typical HUS [57]. Furthermore, in a clinicopathological study of 24 children with HUS (12 of them with typical presentation characterized by a diarrheal prodrome), involvement of the gut (severe colitis) has been reported in a few children leading to death during the acute phase of the disease as well as pancreatic islet cell necrosis leading to diabetes [58], but has never been reported in adult patients with aHUS associated with alternative complement dysregulation.

The overall prognosis of aHUS is poor with a high rate of mortality and recurrence. In the French padiatric cohort (46 children) and the Italian cohort (156 patients; about $30 \%$ adults) 9 and $10 \%$ of patients, respectively, died $[22,24]$. A relapsing course of the disease may occur whatever the genotype underlying the disease as well as in patients with no identified gene mutation $[22,24,26]$. However, the number of relapses is significantly more important in the MCP gene-mutated and in mutationnegative patients. Relapses with complete recovery are mainly characteristic of patients with MCP gene mutations and some patients with no identified mutation. Poor clinical long-term outcome defined as end-stage renal disease (ESRD) is not only seen in patients with an identified gene mutation but also in mutation-negative patients in high frequency (up to 70\% in the registry of German-speaking countries [26]). aHUS associated with MCP gene mutations has the best prognosis of all genotyped cohorts. Renal function is generally preserved for years despite a relapsing course of the disease, although approximately $20-30 \%$ of patients will reach ESRD [22, 24].

Patients with $\mathrm{CFH}$ gene mutations tend to have the worst prognosis with early onset of the disease followed by a relapsing course, and $70 \%$ of cases progress to ESRD or die $[22,24]$. Among the French children, $60 \%$ of those with $\mathrm{CFH}$ gene mutation had either died or reached ESRD by 1 year after disease onset in comparison to $32 \%$ in the group with no identified gene mutation and $0 \%$ of the MCP gene-mutated children [24]. Similar severe clinical outcome with progression to ESRD or death is seen in patients with CFI gene mutations; among the French and Italian cohorts 50 and $70 \%$, respectively, reached ESRD
$[22,24]$. The clinical course and outcome of patients with gain-of-function mutations (i.e. $\mathrm{CFB}$ or $\mathrm{C} 3$ gene mutations) is not well documented in the literature.

\section{Investigation - A Diagnostic Algorithm}

Figure 6 illustrates a diagnostic algorithm which is intended to help physicians to distinguish between 'atypical' and more common forms of HUS based on consensus from expert opinion as evidence is lacking because of the rarity of these disorders. It offers an approach to the current revised classification of HUS, TTP and related disorders from the European Paediatric Research Study group for HUS [11], which helps us to identify the etiology of specific diagnostic subgroups of HUS. It is built up to recognize those cases of HUS that have etiologies other than enterohemorrhagic E. coli or S. dysenteriae type 1 infections (= post-diarrheal (D+) HUS) that are called 'atypical' (= aHUS) and mainly addresses the question: 'How should I investigate a new patient with aHUS?' Whether invasive S. pneumoniae infection-induced HUS should be called 'atypical' or not is still a matter of debate. For a comprehensible illustration in the diagnostic algorithm, this form of HUS is listed separately. Therapeutic strategies in patients with aHUS are discussed below.

Following the recognition of HUS, cases should be allocated to 1 of the 3 clinically recognizable patterns of disease presentation indicated in figure 6 .

(A) Children older than 6 months presenting with diarrhea or bloody diarrhea require investigation to determine the cause of the gastrointestinal infection, including stool cultures, enhancement and selection techniques, gene probes for Stx subtypes and serotyping of the identified enterohemorrhagic enterobacteria, using local microbiological services.

(B) Patients with suspected invasive pneumococcal infection first of all need bacteriological confirmation by blood cultures. $\mathrm{T}$ antigen exposure on red blood cells strongly supports the diagnosis.

(C) All other cases of HUS can be regarded as aHUS and require full investigation (see section 'Investigation - The Clinical Utility of Genetic Screening' below).

\section{Notes on the Algorithm (fig. 6)}

(1) The cutoff point of 6 months is to some extent arbitrary, but exposure to Stx-producing organisms, i.e. enterohemorrhagic E. coli or S. dysenteriae type 1, is less likely before the age of 6 months. Between 1 and 5 years of age, the incidence of Stx (D+) HUS exceeds all other 


\section{Recognition of HUS}

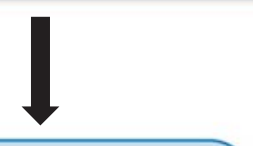

A

Diarrhea or bloody diarrhea in the two weeks before diagnosis of HUS

and

Age $>6$ months 1

and

a) enterohemorrhagic Escherichia coli endemic region

or

b) Shigella dysenteriae type 1 endemic region

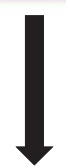

(D+) HUS is likely to be the only cause

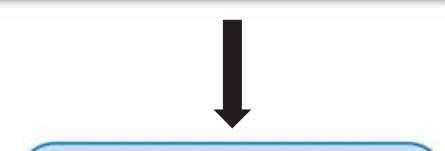

B

Invasive Streptococcus pneumoniae infection (pneumonia, meningitis, septicaemia, especially if there is located infection such as empyema or subdural collection)

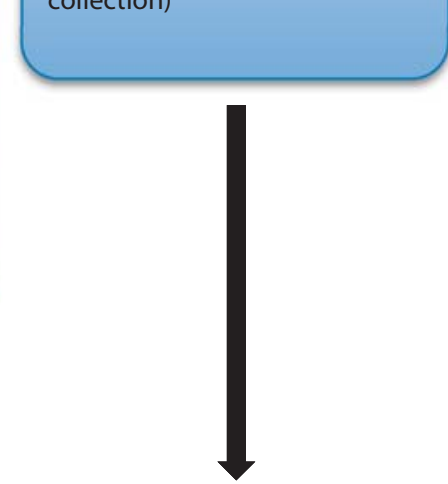

Pneumococcus-induced HUS is likely to be the only cause

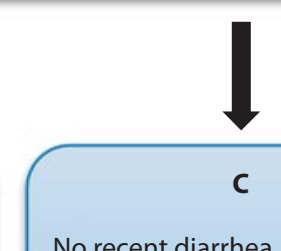

No recent diarrhea

or

Recent diarrhea but one of the following

- manifestation at all ages 1

- insidious onset ${ }^{2}$

- relapse of HUS

- previous unexplained anemia or acute renal failure

- HUS post-transplantation of any organ 3

- asynchronous family history of HUS4

Full investigation for
alternative causes of HUS is
required
Stool culture and investigation
for Stx-producing
enterobacteria is
recommended routinely as
unusual presentations occur
Consider combined host and
environmental factors; i.e.
more than one aetiology is
possible
See section "Investigation -
the clinical utility of genetic
screening"

Fig. 6. Diagnostic algorithm: recognition of aHUS. Letters (A-C) and superscript numbers (1-5) refer to those used in the text. 
causes [1]. On the other hand, aHUS may manifest at all ages. Concerning children, HUS which presents before 6 months of age or in adolescent patients is highly suspicious for aHUS triggered by disorders of complement regulation.

(2) (D+) HUS or HUS induced by pneumococcal infection is rapid in onset. Hemolytic anemia, thrombocytopenia and acute renal failure become apparent over a few days [1]. HUS induced by complement dysregulation or ADAMTS13 disorders can also abruptly occur. However, an insidious onset over more than 1 week, fluctuating clinical signs and laboratory parameters increase the likelihood of a noninfective cause [22, 24].

(3) HUS can follow transplantation of any organ [59, 60]. The role of drugs, especially calcineurin inhibitors, has been suspected but not proven [61]. HUS after renal transplantation raises the question of a host risk factor, whether or not the original cause of the patient's ESRD was known to be HUS.

(4) In an outbreak of infection caused by Stx-producing enterobacteria, family members may develop HUS, either simultaneously (same source of infection) or a few weeks apart (secondary spread). These families do not require investigation beyond confirmation of the infection. By contrast, families with asynchronous HUS are very likely to have inherited risk factors and require full investigation (see also section 'Clinical characteristics of aHUS associated with alternative complement dysregulation').

(5) Stx-producing enterobacteria infection can cause HUS without diarrhea [1]. Also, urinary tract infection caused by Stx-producing enterobacteria is described in the literature [62]. Therefore, screening for Stx-producing organisms has to be done routinely for all patients who are recognized as having HUS.

\section{Investigation - The Clinical Utility of Genetic Screening}

As described above, gene mutations predispose to aHUS rather than they directly cause it. This means that for an individual with a gene mutation the risk of developing aHUS can only be estimated. However, as genotype-phenotype correlations can be seen in those individuals with gene mutations who have developed aHUS, it is clearly helpful to know by which complement mutation an individual is affected. Further, unaffected family members with a known complement mutation should be monitored during periods of increased risk (such as pregnancy and infections).

Update on the Complement System
Considering the therapeutic implications, not only a comprehensive complement analysis in the plasma (i.e. complement $\mathrm{C} 3, \mathrm{C} 4, \mathrm{CFH}, \mathrm{CFI}$, and $\mathrm{CFB}$ antigenic levels), membrane expression of MCP in blood leukocytes and screening for anti-CFH antibodies in any individual with aHUS is mandatory, but also a genetic analysis of the genes encoding complement proteins.

A consensus agreement from the European Working Party on the Genetics of HUS has recently described a screening protocol for the detection of mutations in aHUS [63]. The National Institutes of Health-funded website GeneTests (http://www.genetest.org) provides information on laboratories which offer genetic screening in aHUS.

Concerning complement analysis, it is worth noting that if the C3 level is low, this indicates complement dysregulation but $\mathrm{C} 3$ levels may be normal in patients with complement dysregulation. Further CFH and CFI plasma concentrations may be normal in cases with mutations. Therefore, normal results of C3, CFH and CFI plasma concentrations do not exclude a complement disorder [34]. Investigation of ADAMTS13 activity is indicated routinely to distinguish between 'ADAMTS13-deficiency-related TMA' and 'complement-dysregulation-related TMA'.

\section{Therapeutic Strategies in Patients with aHUS}

In practice, the complex laboratory investigations needed to confirm the etiology take several weeks and genotyping even longer. Therefore, although much progress in understanding the pathogenesis of the disease has been made in the last decade, initial treatment still has to be empirical. Up-to-date recommendations for clinical practice are summarized in table 3.

\section{Plasma Therapy}

There are many reports on plasma therapy in aHUS, but there are no clinical controlled trials. Nevertheless, plasma-based therapies remain the first-line treatment, although evidence is lacking. The recently published guidelines from the European Paediatric Study Group for HUS [64] argue for plasma exchange (PE), replacing it with fresh frozen plasma (FFP) or a standardized whole plasma product such as Octaplas ${ }^{\circledR}$ and recommend to start plasma therapy as early as possible, within $24 \mathrm{~h}$ of presentation, in parallel with conservative treatment (i.e. dialysis, transfusion, antihypertensive treatment, etc.). This is suggested on the basis that PE would remove mu-

Nephron Clin Pract 2010;114:c219-c235 
Table 3. Up-to-date recommendations for the investigation and therapy of patients with aHUS

\section{Investigation}

Nondiarrheal or aHUS is a clinically defined form of TMA characterized by predominant renal involvement and the absence of Stx-producing bacteria as a triggering factor often has relapses and a poorer outcome

Determination of complement C3, C4, CFH, CFI and CFB levels, expression of MCP and screening for anti-CFH antibodies are indicated for all patients with aHUS; normal C3 level does not exclude dysfunction of complement regulation (i.e. regulation of the alternative pathway)

Genotyping of genes encoding the complement regulators $\mathrm{CFH}$, $\mathrm{CFI}$ and MCP and activators $\mathrm{C} 3$ and CFB is indicated for all patients with aHUS, even if plasma levels are normal

The identified gene mutation has to be regarded as a risk factor for aHUS, not as the direct cause. Penetrance of the disease is $50 \%$ in patients with a mutation in complement. Therefore, the risk of developing aHUS is difficult to predict in a family member presenting the mutation. Unaffected family members presenting with a mutation, however, should be monitored during periods of increased risk (such as pregnancy and infections)

A postdiarrheal onset of the disease does not exclude aHUS

\section{Therapy}

PE (with FFP) should be started as early as possible. Benefit is expected mainly in $\mathrm{CFH}$-mutated patients and in patients with anti$\mathrm{CFH}$ antibodies; benefit is also likely in all other groups, except the MCP mutated subgroup, where spontaneous remission generally occurs

The risk of graft loss due to recurrence is high in patients with $\mathrm{CFH}$ and CFI gene mutations, while it is very low in patients with MCP gene mutations

Living donor transplantation is relatively contraindicated because of the risk of graft loss due to recurrence and in family members also because of the risk that donors themselves might have aHUS after donation as a result of unknown genetic factors shared with the recipient

Kidney transplantation under pre-, intra-, and postoperative intensive plasma therapy may be successful in some patients

Combined liver and kidney transplantation under pre- and intraoperative plasma therapy, and postoperative anticoagulation has been successful in a few patients with CFH gene mutations; this option will now have to be considered on an individual basis also for patients with CFI gene mutations, but assessment of the risk/ benefit ratio requires careful and individual attention

Hope for the future relies on therapies which could prevent ESRD, such as $\mathrm{CFH}$ concentrate or anti-C5 monoclonal antibodies tant complement proteins (circulating plasma factors such as CFH, CFI, CFB and C3) responsible for the disease and autoantibodies to CFH or ADAMTS13, while restitution with FFP restores the functional proteins. In addition, PE prevents volume overload and cardiac failure when large amounts of FFP are infused. The European Paediatric Study Group for HUS justifies the urgency and invasive nature of this approach with the fact that TMA of the kidney is a destructive process and that a first episode of the disease may rapidly lead to ESRD. The few patients with a complete quantitative deficiency of complement proteins such as CFH might do well simply with FFP infusions that provide the normal protein. However, the majority of patients have functional deficiency of one or several complement proteins. Thus, PE could be necessary to withdraw mutant proteins as shown by a report of Davin et al. [65] of 2 twin sisters with functional $\mathrm{CFH}$ deficiency secondary to heterozygous $\mathrm{CFH}$ gene mutation. In patients with MCP gene mutations, plasma therapy is not expected to have a direct impact on the course of the disease, as MCP is a resident membrane protein, not a circulating plasma factor. Nevertheless, a potential benefit of PE during relapses, to clear up other triggers of endothelial dysfunction, remains possible. To date, published data indicate that $70-80 \%$ of patients with a mutation in the gene encoding MCP undergo remission from acute episodes, whether or not they have been treated with plasma therapy [22]. PE should be considered as first-line treatment for patients with aHUS associated with anti-CFH antibodies. Steroids and various immunosuppressive treatments, including rituximab, all tried empirically, have been administered to prevent production of antibodies after PE cessation $[49,50,66]$ but are unhelpful interventions used routinely.

Although it was recently established that the coagulation pathways themselves activate complement [67], routine use of anticoagulation is not recommended. However, low-molecular-weight heparin at prophylactic dosages and low-dose aspirin are recommended after combined liver and kidney transplantation (see below).

\section{Transplantation}

Renal transplantation for patients with aHUS cannot be considered without careful preliminary appraisal of the risk of graft loss as a result of disease recurrence. Genotyping the complement regulatory and activating genes now allows a more precise approach to evaluating the posttransplant risk of recurrence in aHUS patients. The risk of disease recurrence after renal transplantation in patients with aHUS has been reviewed [68]. 
Posttransplant Risk of Recurrence and Possible

Prevention

While the risk of posttransplant recurrence is less than $1 \%$ in Stx-associated HUS patients [69], it is approximately $80 \%$ in CFH or CFI gene-mutated patients and most of them lost their graft within 1 year after recurrence [68]. As nonmutated MCP is acquired by the graft, no posttransplant recurrence is expected to occur in MCP gene-mutated patients and these patients can reasonably go to transplantation. Nevertheless, of the 10 MCP gene-mutated patients transplanted and published in the literature, 2 had posttransplant recurrence. One of them most probably had a second mutation in another regulator of the complement system [70]. In the other patient, endothelial microchimerism was suggested by the colonization of the graft endothelia by the recipient's MCP-deficient cells [71]. The risk of recurrence in CFB or C3 gene-mutated patients is not well documented, as to date, there have been only a small number of patients with these genetic defects published in the literature. The risk of recurrence after transplantation in patients with no mutation is about 30\% [68]. These findings underscore the clinical heterogeneity of outcome after renal transplantation in patients with aHUS and highlight the imperative for comprehensive complement analysis and genetic testing prior to renal transplantation in all patients with aHUS.

Avoidance of calcineurin inhibitors for immunosuppression does not lower the incidence of aHUS recurrence after transplantation. As frequency and duration of plasma therapy, therapeutic modalities (PE or FFP infusions) or volume of FFP infused or exchanged to prevent recurrence of aHUS after transplantation were highly variable in historical series, the effect of treatment is difficult to ascertain. Nevertheless, the efficiency of intensive prophylactic plasma therapy started before transplantation seems to have been demonstrated in the past [65] and is consistent with our own experience [72].

Taken into account the risk of graft loss due to recurrence, living donor transplantation is relatively contraindicated, but has to be considered individually and, in addition, in family members, the risk that donors themselves might have aHUS after donation, due to unknown genetic factors shared with the recipient, has to be considered [73].

Combined Liver and Kidney Transplantation

Both CFH and CFI are produced mainly in the liver, and successful liver transplantation would theoretically restore normal complement regulation and prevent disease recurrence. The first 3 combined liver-kidney and auxiliary liver transplantations in children with CFH deficiency were disappointing, as 1 child had severe neurologic sequelae and died 3 years later, 1 child died short after transplantation from primary liver nonfunction and the child with the auxiliary liver transplantation developed posttransplantation lymphoproliferative disease and bacterial sepsis and died 11 months after auxiliary liver transplantation [74]. In the 1 child who died from primary liver nonfunction, autopsy of the liver showed diffuse thrombotic and ischemic lesions, most likely due to the thrombogenic effect of complement activation products deposited on the microvasculature of the liver after transplantation. Taking into account that liver transplantation might trigger intense local complement activation, these initial experiences suggested that liver transplantation should be performed under intensive pre- and perioperative plasma therapy to correct complement dysregulation. The first successful combined liver and kidney transplantation (a 5-year-old male child with CFH deficiency, who had lost a first graft due to recurrence at the age of 2) was reported in 2006 by Saland et al. [74]. The pivotal modification of the transplant procedure was to exchange plasma before transplantation with further plasma supplementation during surgery. This both increased the bioavailability of functional CFH during the critical period needed for the liver graft to recover synthetic functions and, at the same time, removed the endogenous mutant CFH. In addition, posttransplant anticoagulation with low-molecular-weight heparin at prophylactic dosages and low-dose aspirin was used in each of the successful procedures [74]. To date, 3 further successful combined kidney and liver transplantations in patients with $\mathrm{CFH}$ gene mutations (2 children and 1 adolescent patient) have been done [74]. After the success of the initial combined transplantations, a consensus conference on kidney and liver transplantation in aHUS was held in December 2007 and the recommendations have recently been published. In summary, these authors propose combined liver and kidney transplantation as the preferred option for aHUS patients with ESRD and mutations in the $\mathrm{CFH}$ gene and possibly also for patients with mutations in the CFI gene [74]. However, risks associated with this not yet established procedure of combined liver-kidney transplantation still remain, and assessment of the risk/benefit ratio requires careful and individual attention.

Nephron Clin Pract 2010;114:c219-c235 c231 


\section{Way Forward - Future Therapeutic Options}

It seems likely that specific treatments will be needed once the cause of aHUS has been identified. In patients with genetic $\mathrm{CFH}$ abnormalities it seems obvious to give normal CFH. A human plasma-derived CFH concentrate has been developed commercially with that intention, and it received the European orphan drug designation in January 2007. Substitution with CFH concentrate is a therapeutic option for patients with quantitative and functional CFH deficiency but it will have to be taken into account that such commercial concentrates have a short half-life. The same logic applies to aHUS associated with CFI gene mutations but a CFI concentrate is still not available.

Concerning the damage mediated by unregulated complement activation, monoclonal humanized antibodies against the key activating components of the final complement pathway such as $\mathrm{C} 5$ are a promising therapeutic option for patients with aHUS. Prevention of $\mathrm{C} 5$ activation has been shown to ameliorate spontaneous and experimental glomerulonephritis in $\mathrm{CFH}$ deficient mice [75]. The long-term efficacy and tolerance of the anti-C5 monoclonal antibody eculizumab have been demonstrated in large cohorts of patients with paroxysmal nocturnal hemoglobinuria, a well-investigated complement disease [76-78]. To date, 2 cases of aHUS who were unresponsive to PE therapy have been published in the literature, presenting with hematologic and renal improvement after administration of eculizumab: an 18-month-old boy with congenital relapsing aHUS [79] and a 37-year-old woman with aHUS associated with a CFH and CFHR1 gene mutation and recurrence of aHUS 6 weeks after the second kidney transplantation [80]. These data show the positive effect of complement inhibition on the course of aHUS and provide impetus for the evaluation of eculizumab in controlled clinical trials.

\section{Summary}

aHUS is a disorder of alternative pathway dysregulation. A growing list of 'loss-of-function' mutations and polymorphisms in genes encoding regulatory proteins has been demonstrated to predispose to aHUS. Additionally, 'gain-of-function' mutations in complement activation genes have now been associated with aHUS. Recent advances in understanding the pathogenesis of aHUS have clinical significance in predicting renal recovery and transplant outcome. It is important to analyze the complement profile of patients with aHUS, including genetic screening as well. This may also provide opportunities for more specific treatments in the near future, as complement inhibition could represent a therapeutic target in patients with aHUS.

\section{Acknowledgments}

The authors wish to thank Prof. M. Mihatsch for the histological figure. During the past decade the field has progressed extensively and a large number of case reports and excellent papers about aHUS and complement dysregulation have been published. These data are summarized in this review; however, space restrictions allowed only a limited number of citations.

\section{References}

1 Scheiring J, Andreoli SP, Zimmerhackl LB: Treatment and outcome of Shiga-toxin-associated hemolytic uremic syndrome (HUS). Pediatr Nephrol 2008;23:1749-1760.

2 Neumann HPH, Zipfel PF: Hämolytischurämisches Syndrom im Erwachsenenalter. Spektrum Nephrol 2007;1:15-24.

- 3 Furlan M, Robles R, Galbusera M, Remuzzi G, Kyrle PA, Brenner B, Krause M, Scharrer I, Aumann V, Mittler U, Solenthaler M, Lämmle B: Von Willebrand factor-cleaving protease in thrombotic thrombocytopenic purpura and the hemolytic-uremic syndrome. $\mathrm{N}$ Engl J Med 1998;339:1578-1584.
Tsai HM, Lian ECY: Antibodies to von-Willebrand factor-cleaving protease in acute thrombotic thrombocytopenic purpura. N Engl J Med 1998;339:1585-1594.

5 Levy GG, Nichols WC, Lian EC, Foroud T, McClintick JN, McGee BM, Yang AY, Siemieniak DR, Stark KR, Gruppo R, Sarode R, Shurin SB, Chandrasekaran V, Stabler SP, Sabio H, Bouhassira EE, Upshaw JD, Ginsburg D, Tsai HM: Mutations in a member of the ADAMTS gene family cause thrombotic thrombocytopenic purpura. Nature 2001; 413:488-494.
Bianchi V, Robles R, Alberio L, Furlan M, Lämmle B: Von Willebrand factor-cleaving protease (ADAMTS13) in thrombocytopenic disorders: a severely deficient activity is specific for thrombotic thrombocytopenic purpura. Blood 2002;100:710-713.

-7 Vesely SK, George JN, Lämmle B, Studt JD, Alberio L, El-Harake MA, Raskob GE: ADAMTS13 activity in thrombotic thrombocytopenic purpura-hemolytic uremic syndrome: relation to presenting features and clinical outcomes in a prospective cohort of 142 patients. Blood 2003;102:60-68. 
8 Dragon-Durey MA, Frémeaux-Bacchi V: Atypical haemolytic uraemic syndrome and mutations in complement regulator genes. Springer Semin Immunopathol 2005;27: 359-374.

9 Caprioli J, Peng L, Remuzzi G: The hemolytic uremic syndromes. Curr Opin Crit Care 2005; 11:487-492.

$\checkmark 10$ Fakhouri F, Frémeaux-Bacchi V: Does hemolytic uremic syndrome differ from thrombotic thrombocytopenic purpura? Nat Clin Pract Nephrol 2007;3:679-687.

- 11 Besbas N, Karpman D, Landau D, Loirat C, Proesmans W, Remuzzi G, Rizzoni G, Taylor CM, Van de Kar N, Zimmerhackl LB, European Paediatric Research Group for HUS: A classification of hemolytic uremic syndrome and thrombotic thrombocytopenic purpura and related disorders. Kidney Int 2006;70: 423-431.

12 Walport MJ: Complement. First of two parts. N Engl J Med 2001;344:1058-1066.

13 Kohl J: Anaphylatoxins and infectious and non-infectious inflammatory diseases. Mol Immunol 2001;38:175-187.

-14 Schraufstatter IU, Trieu K, Sikora L, Sriramarao P, DiScipio R: Complement C3a and C5a induce different signal transduction cascades in endothelial cells. J Immunol 2002;169:2102-2110.

-15 Watanabe H, Kuraya M, Kasukawa R, Yanagisawa $\mathrm{H}$, Yanagisawa M, Fujita T: Analysis of C5a receptor by monoclonal antibody. J Immunol Methods 1995;185:19-29.

-16 Wiedmer T, Sims PJ: Participation of protein kinases in complement C5b-9-induced shedding of platelet plasma membrane vesicles. Blood 1991;78:2880-2886.

-17 Hughes J, Nangaku M, Alpers CE, Shankland SJ, Couser WG, Johnson RJ: C5b-9 membrane attack complex mediates endothelial cell apoptosis in experimental glomerulonephritis. Am J Physiol Renal Physiol 2000;278:F747-F757.

-18 Nangaku M, Alpers CE, Pippin J, Shankland SJ, Adler S, Kurokawa K, Couser WG, Johnson RJ: A new model of renal microvascular endothelial injury. Kidney Int 1997;52:182194.

-19 Nangaku M, Alpers CE, Pippin J, Shankland SJ, Kurokawa K, Adler S, Johnson RJ, Couser WG: Renal microvascular injury induced by antibody to glomerular endothelial cells is mediated by C5b-9. Kidney Int 1997;52: 1570-1578.

-20 Thompson RA, Winterborn MH: Hypocomplementaemia due to a genetic deficiency of beta $1 \mathrm{H}$ globulin. Clin Exp Immunol 1981; 46:110-119.

-21 Warwicker P, Goodship THJ, Donne RL, Pirson Y, Nicholls A, Ward RM, Turnpenny P, Goodship JA: Genetic studies into inherited and sporadic hemolytic uremic syndrome. Kidney Int 1998;53:836-844.
22 Caprioli J, Noris M, Brioschi S, Pianetti G, Castelletti F, Bettinaglio P, Mele C, Bresin E, Cassis L, Gamba S, Porrati F, Bucchioni S, Monteferrante G, Fang CJ, Liszewski MK, Kavanagh D, Atkinson JP, Remuzzi G: Genetics of HUS: the impact of MCP, CFH, and IF mutations on clinical presentation, response to treatment, and outcome. Blood 2006;108:1267-1279.

23 Frémeaux-Bacchi V, Kemp EJ, Goodship THJ, Dragon-Durey MA, Strain L, Loirat C, Deng HW, Goodship JA: The development of atypical HUS is influenced by susceptibility factors in factor $\mathrm{H}$ and membrane cofactor protein - evidence from two independent cohorts. J Med Genet 2005;42:852-856.

24 Sellier-Leclerc AL, Frémeaux-Bacchi V, Dragon-Durey MA, Macher MA, Niaudet $P$ Guest G, Boudailliez B, Bouissou F, Deschenes G, Gie S, Tsimaratos M, Fischbach M, Morin D, Nivet H, Alberti C, Loirat C: Differential impact of complement mutations on clinical characteristics in atypical hemolytic uremic syndrome. J Am Soc Nephrol 2007; 18:2392-2400.

25 Martinez-Barricarte R, Pianetti G, Gautard R, Misselwitz J, Strain L, Frémeaux-Bacchi V, Skerka CH, Zipfel PF, Goodship THJ, Noris M, Remuzzi G, Rodriguez de Cordoba S, European Working Party on the Genetics of HUS: The complement factor H R1210C mutation is associated with atypical hemolytic uremic syndrome. J Am Soc Nephrol 2008;19:639-646.

26 Neumann HPH, Salzmann M, BohnertIwan B, Mannuelian T, Skerka C, Lenk D, Bender BU, Cybulla M, Riegler P, Königsrainer A, Neyer U, Bock A, Widmer U, Male DA, Franke G, Zipfel PF: Haemolytic uraemic syndrome and mutations of the factor $\mathrm{H}$ gene: a registry based study of Germanspeaking countries. J Med Genet 2003;40: 676-681.

-27 Goicoechea de Jorge E, Harris CL, EsparzaGordillo J, Carreras L, Aller Arranz E, Abarrategui Garrido C, López-Trascasa $M$, Sánchez-Corral P, Morgan BP, de Cordoba SR: Gain-of-function mutations in complement factor B are associated with atypical hemolytic uremic syndrome. Proc Natl Acad Sci USA 2007;104:240-245.

28 Frémeaux-Bacchi V, Regnier $\mathrm{CH}$, DragonDurey MA, Janssen B, Atkinson J: Mutations in complement C3 predispose to development of atypical hemolytic uremic syndrome. Blood 2007;112:4948-4952.

29 Ripoche J, Day AJ, Harris TJ, Sim RB: The complete amino acid sequence of human complement factor H. Biochem J 1988;249: 593-602.

30 Rodriguez de Cordoba S, Esparza-Gordillo J, Goicoechea de Jorge E, Lopez-Trascasa M, Sánchez-Corral P: The human complement factor $\mathrm{H}$ : functional roles, genetic variations and disease associations. Mol Immunol 2004;41:355-367.
31 Kuhn S, Skerka C, Zipfel PF: Mapping of the complement regulatory domains in the human factor $\mathrm{H}$-like protein 1 and in factor $\mathrm{H} 1$. J Immunol 1995;155:5663-5670.

-32 Zipfel PF, Skerka C: Complement factor H and related proteins: an expanding family of complement-regulatory proteins? Immunol Today 1994;15:121-126.

>33 Rodriguez de Cordoba S, Lublin DM, Rubinstein P, Atkinson JP: Human genes for three complement components that regulate the activation of C3 are tightly linked. J Exp Med 1985;161:1189-1195.

-34 Saunders RE, Abarrategui-Garrido C, Frémeaux-Bacchi V, Goicoechea de Jorge E, Goodship THJ, Lopez Trascasa M, Noris M, Ponce Castro IM, Remuzzi G, Rodriguez de Cordoba S, Sánchez-Corral P, Skerka C, Zipfel PF, Perkins SJ: The interactive factor $\mathrm{H}$ atypical hemolytic uremic syndrome mutation database and website: update and integration of membrane cofactor protein and factor I mutations with structural models. Hum Mutat 2007;28:222-234.

>35 Pickering MC, Cook HT: Translational minireview series on complement factor $\mathrm{H}$ : renal diseases associated with complement factor $\mathrm{H}$ : novel insights from humans and animals. Clin Exp Immunol 2008;151:210-230.

36 Atkinson JP, Liszewski MK, Richards A, Kavanagh D, Moulton EA: Hemolytic uremic syndrome. An example of insufficient complement regulation on self-tissue. Ann NY Acad Sci 2005;1056:144-152.

37 Montes T, Goicoechea de Jorge E, Ramos R, Gomà M, Pujol O, Sánchez-Corral $\mathrm{P}$, Rodriguez de Cordoba S: Genetic deficiency of complement factor $\mathrm{H}$ in a patient with agerelated macular degeneration and membranoproliferative glomerulonephritis. Mol Immunol 2008;45:2897-2904.

-38 Rodriguez de Cordoba S, Goicoechea de Jorge E: Translational mini-review series on complement factor $\mathrm{H}$ : genetics and disease associations of human complement factor $\mathrm{H}$. Clin Exp Immunol 2008;151:1-13.

39 Liszewski MK, Leung M, Cui W, Subramanian VB, Parkinson J, Barlow PN, Manchester M, Atkinson JP: Dissecting sites important for complement regulatory activity in membrane cofactor protein (MCP; CD46). J Biol Chem 2000;275:37692-37701.

-40 Riley-Vargas RC, Gill DB, Kemper C, Liszewski MK, Atkinson JP: CD46: expanding beyond complement regulation. Trends Immunol 2004;25:496-503.

41 Richards A, Kemp EJ, Liszewski MK, Goodship THJ, Lampe AK, Decorte R, Müslümanoğlu MH, Kavukcu S, Filler G, Pirson Y, Wen LS, Atkinson JP, Goodship JA: Mutations in human complement regulator, membrane cofactor protein (CD46), predispose to development of familial hemolytic uremic syndrome. Proc Natl Acad Sci USA 2003; 100:12966-12971. 
-42 Frémeaux-Bacchi V, Dragon-Durey MA, Blouin J, Vigneau C, Kuypers D, Boudailliez B, Loirat C, Rondeau E, Fridman WH: Complement factor I: a susceptibility gene for atypical haemolytic uraemic syndrome. J Med Genet 2004;41:E84.

-43 Kavanagh D, Kemp EJ, Mayland E, Winney RJ, Duffield JS, Warwick G, Richards A, Ward R, Goodship JA, Goodship THJ: Mutations in complement factor I predispose to development of atypical hemolytic uremic syndrome. J Am Soc Nephrol 2005; 16:21502155.

-44 Caprioli J, Castelletti F, Bucchioni S, Bettinaglio P, Bresin E, Pianetti G, Gamba S, Brioschi S, Daina E, Remuzzi G, Noris M, International Registry of Recurrent and Familial HUS/TTP: Complement factor $\mathrm{H}$ mutations and gene polymorphisms in haemolytic uraemic syndrome: the C-257T, the A2089G and the G2881T polymorphisms are strongly associated with the disease. Hum Mol Genet 2003;12:3385-3395.

45 Esparza-Gordillo J, Goicoechea de Jorge E, Buil A, Berges LC, López-Trascasa M, Sánchez-Corral P, Rodriguez de Córdoba S: Predisposition to atypical hemolytic uremic syndrome involves the concurrence of different susceptibility alleles in the regulators of complement activation gene cluster in 1q32. Hum Mol Genet 2005; 14:703-712.

46 Pickering MC, Goicoechea de Jorge E, Martinez-Barricarte R, Recalde S, Garcia-Layana A, Rose KL, Moss J, Walport MJ, Cook HT, Rodriguez de Córdoba S, Botto M: Spontaneous hemolytic uremic syndrome triggered by complement factor H lacking surface recognition domains. J Exp Med 2007; 204:1249-1256.

-47 Frémeaux-Bacchi V, Kemp EJ, Goodship JA, Dragon-Durey MA, Strain L, Loirat C, Deng HW, Goodship THJ: The development of atypical haemolytic-uraemic syndrome is influenced by susceptibility factors in factor $\mathrm{H}$ and membrane cofactor protein: evidence from two independent cohorts. J Med Genet 2005;42:852-856.

-48 Esparza-Gordillo J, Goicoechea de Jorge E, Abarrategui Garrido C, Carreras L, LópezTrascasa M, Sánchez-Corral P, Rodriguez de Córdoba S: Insights into hemolytic uremic syndrome: segregation of three independent predisposition factors in a large, multiple affected pedigree. Mol Immunol 2006;43: 1769-1775.

-49 Dragon-Durey MA, Loirat C, Cloarec S, Macher MA, Blouin J, Nivet H, Weiss L, Fridman WH, Frémeaux-Bacchi V: Anti-factor $\mathrm{H}$ autoantibodies associated with atypical hemolytic uremic syndrome. J Am Soc Nephrol 2005; 16:555-563.

50 Józsi M, Strobel S, Dahse HM, Liu WS, Hoyer PF, Oppermann M, Skerka C, Zipfel PF: Anti-factor $\mathrm{H}$ autoantibodies block C-terminal recognition function of factor $\mathrm{H}$ in hemolytic uremic syndrome. Blood 2007;110: 1516-1518.
1 Józsi M, Licht C, Strobel S, Zipfel SL, Richter H, Heinen S, Zipfel PF, Skerka C: Factor H autoantibodies in atypical hemolytic uremic syndrome correlate with CFHR1/CFHR3 deficiency. Blood 2008;111:1512-1514.

52 Fang CJ, Frémeaux-Bacchi V, Liszewski MK, Pianetti G, Noris M, Goodship THJ, Atkinson JP: Membrane cofactor protein mutations in atypical hemolytic uremic syndrome (aHUS), fatal Stx-HUS, C3 glomerulonephritis and the HELLP syndrome. Blood 2007;111:624-632.

53 Edey MM, Mead PA, Saunders RE, Strain L, Perkins SJ, Goodship THJ, Kanagasundaram NS: Association of a factor $\mathrm{H}$ mutation with hemolytic uremic syndrome following a diarrheal illness. Am J Kidney Dis 2008;51: 487-490.

54 Noris M, Remuzzi G: Hemolytic uremic syndrome. J Am Soc Nephrol 2005;16:10351050.

55 Eriksson KJ, Boyd SG, Tasker RC: Acute neurology and neurophysiology of haemolyticuraemic syndrome. Arch Dis Child 2001;84: 434-435.

56 Larakeb A, Leroy S, Frémeaux-Bacchi V, Montchilova M, Pelosse B, Dunand O, Deschênes G, Bensman A, Ulinski T: Ocular involvement in hemolytic uremic syndrome due to factor $\mathrm{H}$ deficiency - are there therapeutic consequences? Pediatr Nephrol 2007; 22:1967-1970.

57 Sturm V, Menke MN, Landau K, Laube GF, Neuhaus TJ: Ocular involvement in paediatric haemolytic uraemic syndrome. Acta Ophthalmol 2009, E-pub ahead of print.

58 Argyle JG, Hogg RJ, Ryslier TJ, Silva FG, Siegler RL: A clinicopathological study of 24 children with hemolytic uremic syndrome. Pediatr Nephrol 1990;4:52-58.

59 Bonser RS, Adu D, Franklin I, McMaster P: Cyclosporin-induced haemolytic uraemic syndrome in liver allograft recipient. Lancet 1984;2:1337.

60 Moake JL, Byrnes JJ: Thrombotic microangiopathies associated with drugs and bone marrow transplantation. Hematol Oncol Clin North Am 1996;10:485-497.

61 Abraham KA, Little MA, Dorman AM, Walshe JJ: Hemolytic-uremic syndrome in association with both cyclosporine and tacrolimus. Transpl Int 2000;13:443-447.

62 Hogan MC, Gloor JM, Uhl JR, Cockerill FR, Milliner DS: Two cases of non-O157:H7 Escherichia coli hemolytic uremic syndrome caused by urinary tract infection. Am J Kidney Dis 2001;38:E22.

63 Kavanagh D, Richards A, Frémeaux-Bacchi V, Noris M, Goodship THJ, Remuzzi G, Atkinson JP: Screening for complement system abnormalities in patients with atypical hemolytic uremic syndrome. Clin J Am Soc Nephrol 2007;2:591-596.
64 Ariceta G, Besbas N, Johnson S. Karpman D, Landau D, Licht C, Loirat C, Pecoraro C, Taylor C, Van De Kar N, Van De Walle J, Zimmerhackl L: Guideline for the investigation and initial therapy of diarrhea-negative hemolytic uremic syndrome. Pediatr $\mathrm{Ne}$ phrol 2009;24:687-696.

65 Davin JC, Olie KH, Verlaak R, Horuz F, Florquin S, Weening JJ, Groothoff JW, Strain L, Goodship TH: Complement factor $\mathrm{H}$-associated atypical hemolytic uremic syndrome in monozygotic twins: concordant presentation, discordant response to treatment. Am J Kidney Dis 2006;47:e27-e30.

-66 Kwon T, Dragon-Durey MA, Macher MA, Baudouin V, Maisin A, Peuchmaur M, Frémeaux-Bacci V, Loirat C: Successful pretransplant management of a patient with anti-factor $\mathrm{H}$ autoantibodies-associated haemolytic uraemic syndrome. Nephrol Dial Transplant 2008;23:2088-2090.

67 Amara U, Rittirsch D, Flierl M, Brückner U, Klos A, Gebhard F, Lambris JD, Huber-Lang $\mathrm{M}$ : Interaction between the coagulation and complement system. Adv Exp Med Biol 2008; 632:71-79.

68 Loirat C, Frémeaux-Bacci V: Hemolytic uremic syndrome recurrence after renal transplantation. Pediatr Transplant 2008;12:619629.

69 Loirat C, Niaudet P: The risk of recurrence of hemolytic uremic syndrome after renal transplantation in children. Pediatr Nephrol 2003;18:1095-1101.

70 Frémeaux-Bacchi V, Moulton EA, Kavanagh D, Dragon-Durey MA, Blouin J, Caudy A, Arzouk N. Cleper R, Francois M, Guest G, Pourrat J, Seligman R, Fridman WH, Loirat C, Atkinson JP: Genetic and functional analyses of membrane cofactor protein (CD46) mutations in atypical hemolytic uremic syndrome. J Am Soc Nephrol 2006;17:20172025

-71 Frémeaux-Bacchi V, Arzouk N, Ferlicot S, Charpentier B, Snanoudj R, Dürrbach A: Recurrence of HUS due to CD46/MCP mutation after renal transplantation: a role for endothelial microchimerism. Am J Transplant 2007;7:2047-2051.

-72 Hirt-Minkowski P, Schaub S, Mayr M, Schifferli JA, Dickenmann M, FrémeauxBacchi V, Steiger J: Hemolytic uremic syndrome caused by factor $\mathrm{H}$ mutation: is single kidney transplantation under intensive plasmatherapy an option? Nephrol Dial Transplant 2009;24:3548-3551.

73 Donne RL, Abbs I, Barany P, Elinder CG, Little M, Conlon P, Goodship THJ: Recurrence of hemolytic uremic syndrome after live related renal transplantation associated with subsequent de novo disease in the donor. Am J Kidney Dis 2002;40:e22.

74 Saland JM, Ruggenenti P, Remuzzi G, Consensus Study Group: Liver-kidney transplantation to cure atypical hemolytic uremic syndrome. J Am Soc Nephrol 2008;20:940949. 
75 Pickering MC, Warren J, Rose KL, Carlucci F, Wang Y, Walport MJ, Cook HT, Botto M: Prevention of C5 activation ameliorates spontaneous and experimental glomerulonephritis in factor $\mathrm{H}$-deficient mice. Proc Natl Acad Sci USA 2006;103:9649-9654.

76 Hillmen P, Hall C, Marsh JC, Elebute M, Bombara MP, Petro BE, Cullen MJ, Richards SJ, Rollins SA, Mojcik CF, Rother RP: Effect of eculizumab on hemolysis and transfusion requirements in patients with paroxysmal nocturnal hemoglobinuria. N Engl J Med 2004;350:552-559.

77 Hillmen P, Young NS, Schubert J, Brodsky RA, Socié G, Muus P, Röth A, Szer J, Elebute MO, Nakamura R, Browne P, Risitano AM, Hill A, Schrezenmeier H, Fu CL, Maciejewski J, Rollins SA, Mojcik CF, Rother RP, Luzzatto L: The complement inhibitor eculizumab in paroxysmal nocturnal hemoglobinuria. N Engl J Med 2006;335: 1233-1243.
-78 Brodsky RA, Young NS, Antonioli E, Risitano AM, Schrezenmeier H, Schubert J, Gaya A, Coyle L, de Castro C, Fu CL, Maciejewski JP, Bessler M, Kroon HA, Rother RP, Hillmen P: Multicenter phase 3 study of the complement inhibitor eculizumab for the treatment of patients with paroxysmal nocturnal hemoglobinuria. Blood 2008;111:1840 1847.

79 Gruppo RA: Eculizumab for congenital atypical hemolytic-uremic syndrome. N Engl J Med 2009;360:544-546.
$>80$ Nürnberger J, Witzke O, Opazo Saez A, Vester U, Baba HA, Kribben A, Zimmerhackl LB, Janecke AR, Nagel M, Kirschfink M: Eculizumab for atypical hemolytic-uremic syndrome. N Engl J Med 2009;360:542544.

81 Symmers WSC: Thrombotic microangiopathic haemolytic anemia (thrombotic microangiopathy). Br Med J 1952;2:897-903.

82 Moschcowitz E: An acute febrile pleiochromic anemia with hyaline thrombosis of the terminal arterioles and capillaries: an undescribed disease. Proc NY Pathol Soc 1924;2124. Reprinted in Mt Sinai J Med 2003;70:322325.

-83 Gasser C, Gautier E, Steck A, Siebenmann RE, Oechslin R: Hemolytic-uremic syndrome: bilateral necrosis of the renal cortex in acute acquired hemolytic anemia (in German). Schweiz Med Wochenschr 1955;85: 905-909.

\section{Editorial Comment}

\section{El Nahas, Sheffield}

The minireview by Hirt-Minkowski and colleagues from Basel updates the reader on recent advances in the understanding of the genetics, pathophysiology and management of atypical hemolytic uremic syndrome. It sheds light on the rapidly expanding number of genetic mutations involving the complement system: complement factor $\mathrm{H}(\mathrm{CFH})$, membrane cofactor protein, complement factor I, complement factor B and C3 as well as thrombomodulin. Complement component activation, dysfunction or inactivation by autoantibodies seems to play a predominant role in the pathogenesis of this condition. The review also examines the rationale behind cur- rent and established therapies such as plasma exchange with fresh frozen plasma or plasma products such as Octaplas, namely the removal of dysfunctional complement components and/or autoantibodies and replacement with normal plasma components. It also explores new therapies aimed at modulating the complement system including anti-C5 monoclonal antibodies (eculizumab) and a human plasma-derived $\mathrm{CFH}$ concentrate. This is a rare disease where nephrology has made huge strides in the last decade. It exemplifies a condition where a better understanding of genetics sheds light on pathophysiology and leads to new therapies. 